\title{
Tuning the Emission Color of Hydrothermally Synthesized Carbon Quantum Dots by Precursor Engineering
}

\author{
Mai Xuan Dung ${ }^{1, *}$, Mai Van Tuan ${ }^{2,3}$, Pham Truong Long ${ }^{4}$, Nguyen Thi Mai ${ }^{1}$ \\ ${ }^{I}$ Department of chemistry, Hanoi Pedagogical University 2, Xuan Hoa, Phuc Yen, Vinh Phuc, Vietnam \\ ${ }^{2}$ School of Engineering Physics, Hanoi University of Science and Technology, \\ 1 Dai Co Viet, Hanoi, Vietnam \\ ${ }^{3}$ Faculty of Fundamental Sciences, Electric Power University, 235 Hoang Quoc Viet, Hanoi, Vietnam \\ ${ }^{4}$ Department of Natural Sciences, Can Tho University, Ninh Khanh, Ninh Kieu, Can Tho, Vietnam
}

Received 26 November 2018

Revised 11 March 2019; Accepted 14 March 2019

\begin{abstract}
Water-soluble, biocompatible, and high luminescence carbon quantum dots (CQDs) have been successfully synthesized from citric acid (CA) and ethylenediamine (EDA) using different approaches. Although the emission quantum yield of CQDs could be as high as $80 \%$, their emission spectrum is usually dominated by surface fluorophore groups and maximized at about $450 \mathrm{~nm}$. This paper examines the effects of acid and amine precursors on the photoluminescence (PL) of resulted CQDs by systematically comparing the optical properties of CQDs obtained from CA, PA (phthalic acid) with EDA, ANL (aniline). UV-vis and PL spectroscopic studies revealed that the absorption onset varied from $325 \mathrm{~nm}$ to $400 \mathrm{~nm}$ while PL maximum changed from $390 \mathrm{~nm}$ to 450 $\mathrm{nm}$ by engineering acid and amine precursors. The emission quantum yield was also changed from $9 \%$ to $70 \%$, depending on the used acid-amine precursors.

Keywords: Carbon quantum dots, hydrothermal synthesis, colour tuning, photoluminescence, acid, amine.
\end{abstract}

\section{Introduction}

Carbon quantum dots (CQDs) are a new member of carbon nanomaterials including

\footnotetext{
*Corresponding author.

Email address: xdmai@hpu2.edu.vn
}

https://doi.org/10.25073/2588-1140/vnunst.4831 carbon nanotube, fullerenes, and graphene that have been widely implemented in diverse applications. Novel properties of CQDs including biocompatibility [1] and color tunability [2] that have been demonstrated previously attract broad attention with a hope to replace Cd-based QDs many applications where the photoluminescence properties of QDs are 
utilized such as biosensors, chemical sensors, light-emitting diodes (LEDs), and immune analysis. When compared with mature nontoxic QDs, e.g. InP [3], Si [4-7] or visible luminescence $\mathrm{ZnO}$ particle [8], CQDs have advantages of large chemical abundance and cost-effective synthesis but the information relating to chemical structures and photoluminescence origin of CQDs is lag behind. Among a vast number of reported CQDs, CQDs derived from CA and EDA are probably the CQDs that have been described in most detail [9-11]. We synthesized successfully highly luminescence CQDs whose emission quantum yield is of $80 \%$ from CA and EDA by a simple hydrothermal method [12, 13]. CQDs with a quantum yield as high as $23 \%$ could also be synthesized using various fruit juices [14] by the same procedure. It turned out a fundamental issue that most of CQDs samples emit blue light and have a broad emission spectrum.

a)
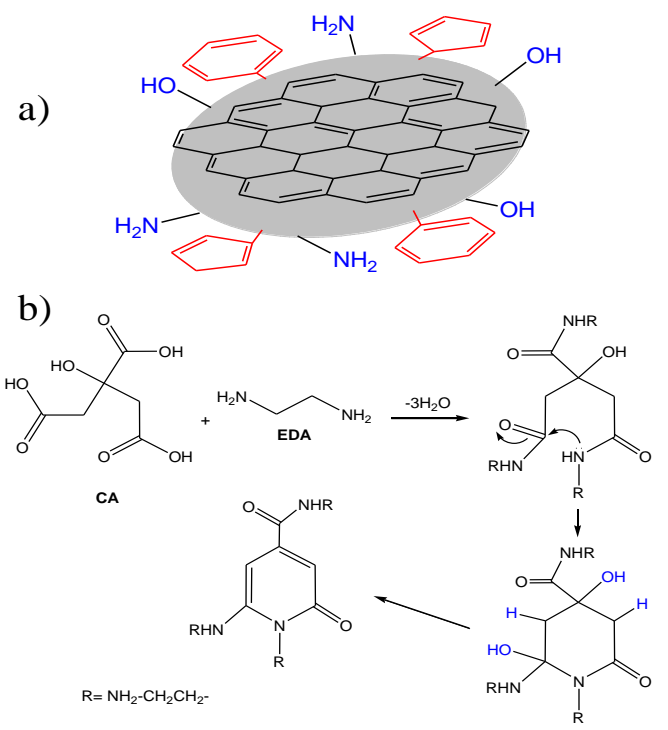

Figure 1. a) A conceptual structure of a carbon quantum dot that contains polyaromatic hydrocarbon core (PAH), surface polar groups (SPG) and surface fluorophore (SF). b) The formation of SF from CA and EDA.

Recent spectroscopic studies have proposed a debate on structure of CQDs derived from CA and EDA as schematically drawn in Fig. 1a [9-
11]. Briefly, CQDs contains at least three main components namely a carbon core that involves polyaromatic hydrocarbon (PAHs) of different sizes, simple surface polar groups (SPG), e.g. $\mathrm{OH}$, -NH-.

$\mathrm{COOH}$, etc, and surface fluorophore (SF). During the course of hydrothermal synthesis, SF groups are formed from the condensation between CA and EDA as shown in Fig. 1b following by carbonization processes forming PAHs [10, 15]. While SPG endows water solubility of CQDs, PAH, SF and their interactions govern the optical properties of CQDs [16]. This conceptual finding gives a worthy guideline to tune the emission spectrum of CQDs by varying SF via precursor or solvent engineering [17] or by tuning PAH-SF interactions [11]. Herein, we explored the ideal that SF could be changed, and hence the emission spectrum of resulting CQDs, by varying acid and amine precursors. Indeed, we synthesized CQDs using different couples of an acid and an amine among citric acid (CA), phthalic acid (PA), ethylenediamine (EDA) and aniline (ANL) and showed that their PL maximum varied from $390 \mathrm{~nm}$ to $450 \mathrm{~nm}$.

\section{Experimental section}

\subsection{The synthesis of $C Q D s$}

All chemicals including CA, EDA, ANL, and PA were purchased from Aladdin Chemical and used without any further purification. Acetone and ethanol (HPLC grade) were obtained from Xilong Chemical. For the synthesis of CQDs, first CA or PA was dissolved in a mixture of $25 \mathrm{ml}$ of double distillated water and $15 \mathrm{ml}$ of ethanol to perform $0.5 \mathrm{M}$ solutions. A calculated volume of liquid amines was then added to the acidic solution so that the molar ratio between acidic group $(-\mathrm{COOH})$ and amine $\left(-\mathrm{NH}_{2}\right)$ was 1 . The mixture was transferred into a Teflon-lined in stainless steel autoclave, which was then heated by a oven at $200^{\circ} \mathrm{C}, 230^{\circ} \mathrm{C}$ or $260^{\circ} \mathrm{C}$ for 6 hours. For purification, acetone was added to the reaction mixture to precipitate CQDs which 
was then collected by mean of centrifugation. The precipitating and centrifugation processes were repeated twice.

\subsection{Characterizations}

FTIR (fourier transform infrared) spectra were performed on a Jasco FT/IR6300 spectrometer. The absorption spectra of CQDs dissolved in water were conducted on a UV2450 (Shimadzu) spectrometer. The emission spectra of CQD and quinine sulfate solutions were carried out on a Nanolog spectrometer. TEM (transmission electron microscopy) images of CQDs were obtained on a JEM 2100 microscope. XPS (X-ray photoelectron spectroscopy) spectra was analyzed by an ULVAC PHI 500 (Versa Probe II).

To calculate the emission quantum yield of CQDs, we measured UV-vis absorption and PL spectra of CQDs dissolved in water and quinine sulfate dissolved in $\mathrm{H}_{2} \mathrm{SO}_{4} 0.5 \mathrm{M}$ using the same conditions. The concentration of solutes was adjusted so that the absorbance at $325 \mathrm{~nm}$ was about 0.1 . The emission quantum yield of CQDs was then calculated using equation:

$$
Q_{S}=Q_{R} \times \frac{I_{S}}{I_{R}} \times \frac{A_{R}}{A_{S}} \times \frac{\eta_{S}^{2}}{\eta_{R}^{2}}
$$

where $Q_{R}$ of $54 \%$ is the standard quantum yield of quinine sulfate; $I, A, \eta$ are integrated PL intensity, absorbance at excitation wavelength and refractive index of solution; $S$ and $R$ subscripts refer to sample and quinine sulfate, respectively.

\section{Results and discussions}

We first optimized the hydrothermal temperature by comparing the UV-vis and PL (excited at $325 \mathrm{~nm}$ ) of CQDs samples as shown in Fig. 2.
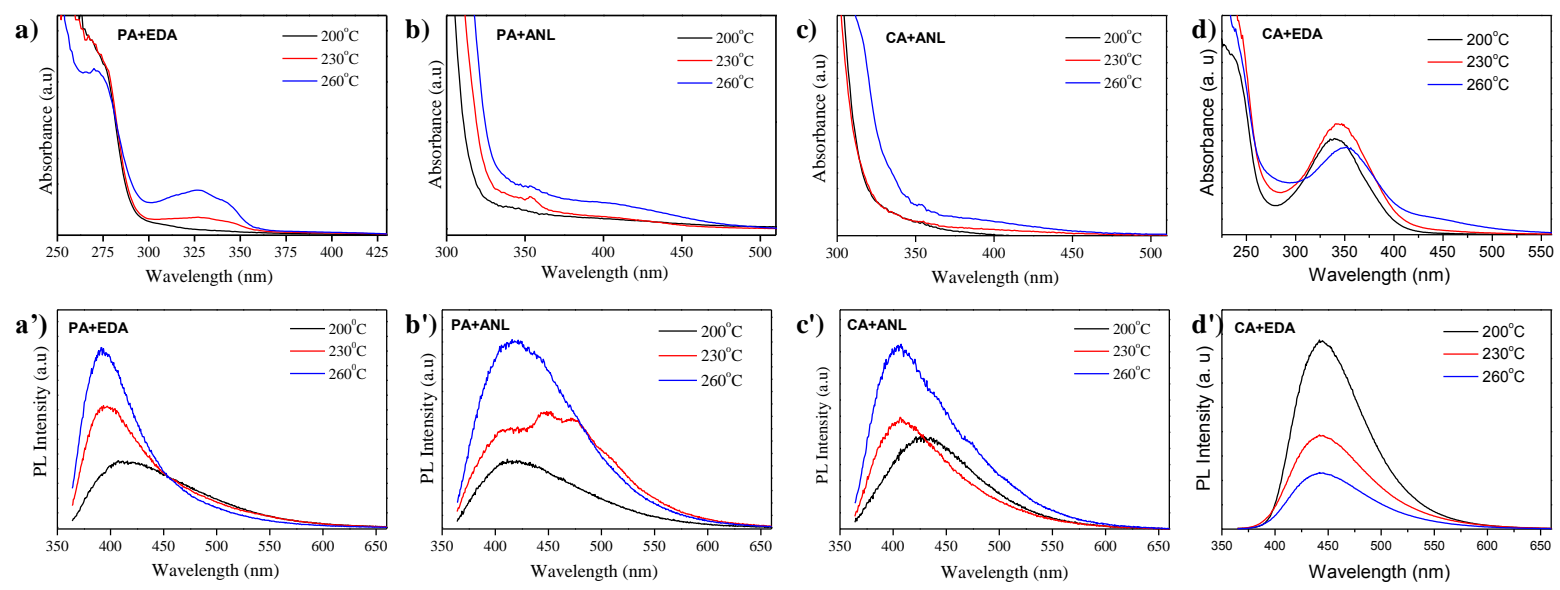

Figure 2. UV-vis absorption (above) and PL spectra (below) of CQDs obtained by using a) PA + EDA; b) $\mathrm{PA}+\mathrm{ANL}$; c) $\mathrm{CA}+\mathrm{ANL}$; and d) $\mathrm{CA}+\mathrm{EDA}$.

When EDA was involved, a visible absorption band appeared at about $325 \mathrm{~nm}$ $350 \mathrm{~nm}$ in PA+EDA and CA+EDA samples. This band is attributed to surface fluorophore as shown in Fig. 1b for the case CA+EDA [15]. For the case of PA+EDA, the absorption band centered at about $325 \mathrm{~nm}$ and PL intensity reached maximum at $260^{\circ} \mathrm{C}$, which is very near to safety point of hydrothermal vessel. We then chose $260^{\circ} \mathrm{C}$ as optimal temperature for the synthesis of CQDs from PA and EDA. For the case of CA+EDA, PL reached maximum at $200^{\circ} \mathrm{C}$, which was then selected as optima temperature for the synthesis of CQDs from CA and EDA.

In contrast to $\mathrm{PA}+\mathrm{EDA}$ or $\mathrm{CA}+\mathrm{EDA}, \mathrm{CQDs}$ derived from $\mathrm{PA}+\mathrm{ANL}$ and $\mathrm{CA}+\mathrm{ANL}$ exhibited featureless UV-vis absorption spectra and an 
absorption tail extending over $450 \mathrm{~nm}$. The PL got maximum intensity at $260^{\circ} \mathrm{C}$, the optimal temperature for the synthesis of CQDs from $\mathrm{PA}+\mathrm{ANL}$ or $\mathrm{CA}+\mathrm{ANL}$.

The emission quantum yields of CQDs were estimated by comparing their PL intensity with that quinine sulfate whose standard emission yield of $54 \%$. The results shown in table 1 indicate that the emission yield of CQDs depends largely on precursors.

Table 1. Emission quantum yield at $325 \mathrm{~nm}$ excitation (Q), diameter (D) and PL max position (PL) of CQDs.

\begin{tabular}{lllll}
\hline & PA+EDA & PA+ANL & CA+ANL & CA+EDA \\
\hline $\begin{array}{l}\text { Q } \\
(\%)\end{array}$ & 15.4 & 9.3 & 6.9 & 70 \\
$\begin{array}{l}\mathrm{D} \\
(\mathrm{nm})\end{array}$ & 4.8 & 6.0 & 7.1 & 8.1 \\
$\begin{array}{l}\mathrm{PL} \\
(\mathrm{nm})\end{array}$ & 390 & 420 & 406 & 450 \\
\hline
\end{tabular}

To study roughly the surface chemistry of CQDs, FT-IR spectra were conducted and shown in Fig. 3a. Some notable absorption bands at $2900 \mathrm{~cm}^{-1}, 1730 \mathrm{~cm}^{-1}, 1650 \mathrm{~cm}^{-1}$, and $1550 \mathrm{~cm}^{-1}$ are marked. The absorption band at $2900 \mathrm{~cm}^{-1}$ can be attributed to C-H bending of saturated hydrocarbon. The absorption bands at $1730 \mathrm{~cm}^{-1}$ and $1652 \mathrm{~cm}^{-1}$ are assigned to $\mathrm{C}=\mathrm{O}$ bending in the carboxylate (-COO) and amide ($\mathrm{CONH})$ groups, respectively. The absorption band at $1550 \mathrm{~cm}^{-1}$ is due to $\mathrm{N}-\mathrm{H}$ bending in amide groups. Additionally, $\mathrm{CA}+\mathrm{EDA}$ and PA+EDA had a broad absorption band in 3000$3500 \mathrm{~cm}^{-1}$ region, which originates from the vibrations of polar $\mathrm{N}-\mathrm{H}$ or $\mathrm{O}-\mathrm{H}$ groups. The existence of $-\mathrm{NH},-\mathrm{OH},-\mathrm{COO}$ and $-\mathrm{CONH}-$ groups explains why CQDs are soluble well in water.

Additionally, we conducted XPS analysis to evaluate chemical content of CQDs. Fig. 3b shows XPS survey spectrum of CQDs obtained from CA and EDA. It exhibits three elemental signals with binding energies of $285 \mathrm{eV}, 399$
$\mathrm{eV}$, and $531 \mathrm{eV}$ which correspond to binding energies of $\mathrm{C} 1 \mathrm{~s}, \mathrm{~N} \mathrm{1s}$ and O1s. Therefore, CQDs derived from CA and EDA are nitrogendoped carbon quantum dots.
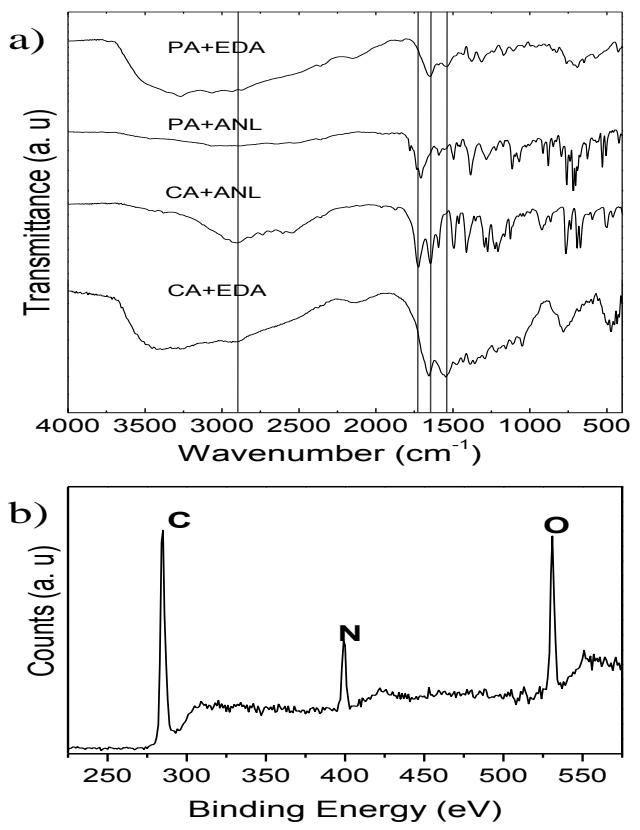

Figure 3. a) FT-IR spectra of CQDs;

b) XPS spectrum of CQDs obtained from mixture of CA and EDA.

To correlate the optical properties shown in Fig. 2 with the structure, TEM images of CQDs were conducted and are summarized in Fig. 4. UV-Vis absorption and normalized PL spectra (at $325 \mathrm{~nm}$ excitation) are also shown in Fig. 5 for comparison. In TEM images of all samples, there were big aggregates that could be attributed to H-bonded CQDs system formed as solvent evaporating in TEM sampling process. In addition, the grey contrast varied from dot to dot, indicating different degrees of carbonization of the carbon core, the common feature of CQDs obtained by hydrothermal methods $[11,15]$. The size distribution of CQDs was estimated from TEM images and summarized in Fig. 4 
a)
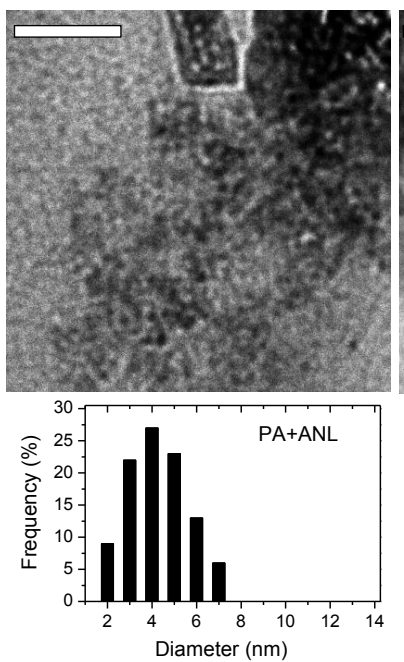

b)
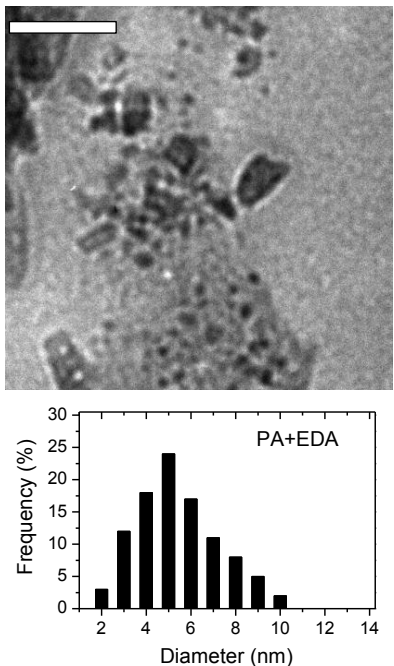

c)
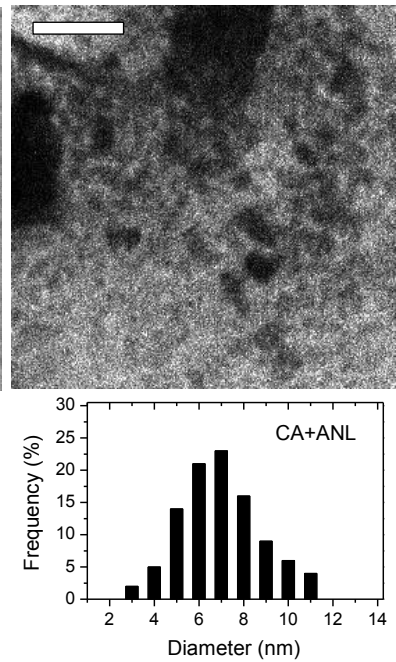

d)
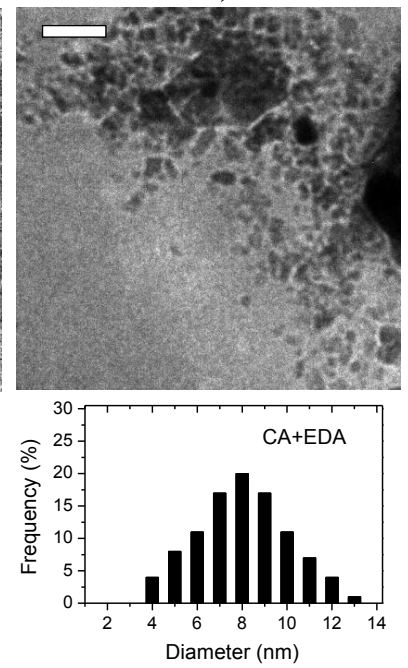

Figure 4. TEM images (above) and size distribution (below) of CQDs obtained from a) PA+ANL, b) $\mathrm{PA}+\mathrm{EDA}$, c) $\mathrm{CA}+\mathrm{ANL}$, and d) CA+EDA. The scaling bar is $50 \mathrm{~nm}$.
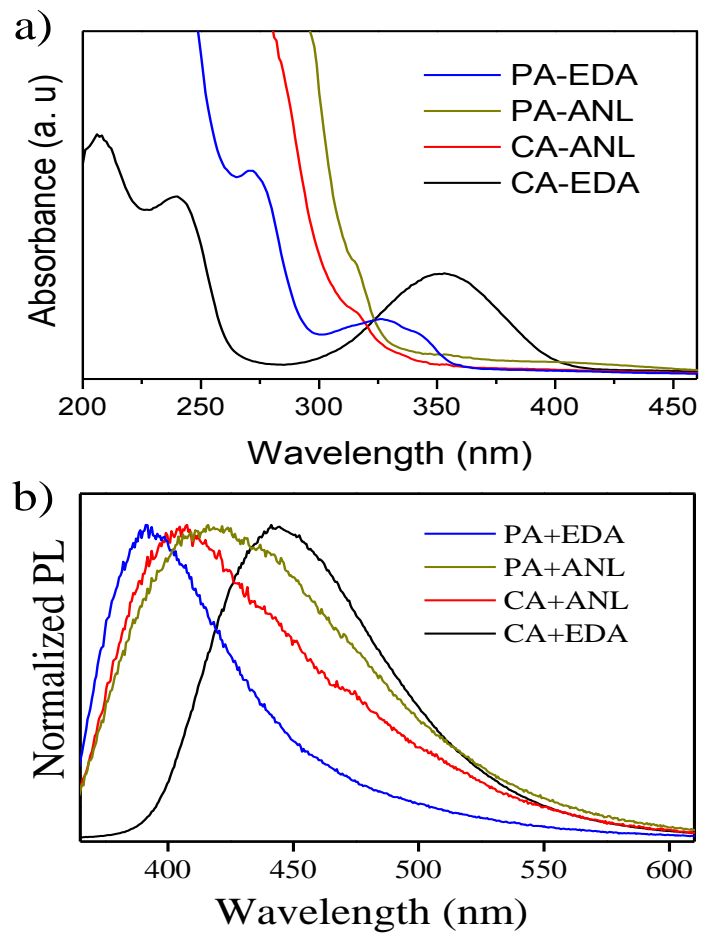

Figure 5. Normalized UV-vis (a) and PL (b) spectra (excited at $325 \mathrm{~nm}$ ) of CQDs.
The average diameter of CQDs was about $4.8 \mathrm{~nm}$ for PA+ANL, $6 \mathrm{~nm}$ for PA+EDA, 7.1 $\mathrm{nm}$, for $\mathrm{CA}+\mathrm{ANL}$ and $8.1 \mathrm{~nm}$ for CA+EDA samples, respectively. We did not observed a clear correlation between the diameter variation with the trend in the emission quantum yield or the optical shifts shown in Fig. 5b and summarized in table 1 . It is probably due to the complexity in the structure of CQDs. As mentioned previously, CQDs involve PAHs and fluorophore groups. While the size visualized by TEM may relate to the dimension of PAHs, the surface fluorophore groups govern mostly the optical properties of CQDs. Hydrothermal treatment of different mixtures of acids and amines resulted in different surface fluorophores and hence different optical properties including emission quantum yield, PL max position and absorption region [18]. We think that comparison between CQDs of different sizes but having the same functional groups is needed to realize the size-dependent optical properties. 


\section{Conclusion}

Water soluble CQDs were synthesized by a hydrothermal method using mixtures of an acid (CA or PA) and an amine (ANL or EDA). By engineering the precursor, absorption onset on CQD could be controlled from $325 \mathrm{~nm}$ to 400 $\mathrm{nm}$ while emission center could be tuned from $390 \mathrm{~nm}$ to $450 \mathrm{~nm}$. CQDs that had the highest emission quantum yield of $70 \%$ were nitrogendoped quantum dots with an average particle size of $8.1 \mathrm{~nm}$. The results demonstrated herein pave a way to control the optical properties of water-soluble CQDs by engineering precursor.

\section{Acknowledgements}

This research is funded by Vietnam Ministry of Education and Training, Science and Technology Foundation of Hanoi Pedagogical University 2 via project number B.2018-SP2-13.

\section{References}

[1] K. Wang, Z. Gao, G. Gao, Y. Wo, Y. Wang, G. Shen, D. Cui, Systematic safety evaluation on photoluminescent carbon dots, Nanoscale Res. Lett. 8 (2013) 1-9. https://doi.org/10.1186/1556276X-8-122.

[2] K. Jiang, S. Sun, L. Zhang, Y. Lu, A. Wu, C. Cai, H. Lin, Red, Green, and Blue Luminescence by Carbon Dots: Full-Color Emission Tuning and Multicolor Cellular Imaging, Angew. Chemie Int. Ed. 54 (2015) 5360-5363. https://doi.org/10.1002 /anie.201501193.

[3] M.X. Dung, P. Mohapatra, J.K. Choi, J.H. Kim, S. Jeong, H.D. Jeong, InP quantum dotorganosilicon nanocomposites, Bull. Korean Chem. Soc. 33 (2012) 1491-1504. https://doi.org/ 10.5012/bkcs.2012.33.5.1491.

[4] X. Mai, Q. Hoang, The Large-Scale Synthesis of Vinyl-Functionalized Silicon Quantum Dot and Its Application in Miniemulsion Polymerization, J. Nanomater. 2016 (2016) Article ID 2490235, 7 pages. http://dx.doi.org/10.1155/2016/2490235.
[5] M.X. Dung, D.D. Tung, S. Jeong, H.D. Jeong, Tuning optical properties of $\mathrm{Si}$ quantum dots by pi-conjugated capping molecules, Chem. - An Asian J. 8 (2013) 653-664. https://doi.org/ 10.1002/asia.201201099.

[6] M.X. Dung, H.D. Jeong, Synthesis of styrylterminated silicon quantum dots: Reconsidering the use of methanol, Bull. Korean Chem. Soc. 33 (2012) 4185-4187. https://doi.org/10.5012/bkcs. 2012.33.12.4185.

[7] V.T. Mai, N.H. Duong, X.-D. Mai, Surface Polarity Controls the Optical Properties of OnePot Synthesized Silicon Quantum Dots, Chem. Phys. 518 (2018) 107-111. https://10.1016/ j.chemphys.2018.11.012.

[8] V.T. Mai, Q. Hoang, X. Mai, Enhanced Red Emission in Ultrasound-Assisted Sol-Gel Derived ZnO/PMMA Nanocomposite, Adv. Mater. Sci. Eng. 2018 (2018) 1-8. https://10.1155/2018/ 7252809 .

[9] J. Schneider, C.J. Reckmeier, Y. Xiong, M. Von Seckendorff, A.S. Susha, P. Kasak, A.L. Rogach, Molecular fluorescence in citric acid-based carbon dots, J. Phys. Chem. C. 121 (2017) 2014-2022.

https://10.1021/acs.jpcc.6b12519.

[10] F. Ehrat, S. Bhattacharyya, J. Schneider, A. Löf, R. Wyrwich, A.L. Rogach, J.K. Stolarczyk, A.S. Urban, J. Feldmann, Tracking the Source of Carbon Dot Photoluminescence: Aromatic Domains versus Molecular Fluorophores, Nano Lett. 17 (2017) 7710-7716. https://10.1021/ acs.nanolett. $7 \mathrm{~b} 03863$.

[11] M. Shamsipur, A. Barati, A.A. Taherpour, M. Jamshidi, Resolving the Multiple Emission Centers in Carbon Dots: From Fluorophore Molecular States to Aromatic Domain States and Carbon-Core States, J. Phys. Chem. Lett. 9 (2018) 4189-4198. https://10.1021/acs.jpclett.8b02043.

[12] T.H.T. Xuan-Dung Mai, Quang-Bac Hoang, Hong Quan To, Phuong Le Thi, Tổng hợp chấm lượng tử carbon với hiệu suất phát quang cao, Tạp chí Khoa học - Đại học Sư phạm Hà Nội 2. 47 (2017) 20-26.

[13] M.X.D. Lê Thị Phượng, Lê Quang Trung, Đỗ Thị Thu Hòa, Doãn Diệu Thúy, Ảnh hưởng của tỷ lệ Acid/Amine đến cấu trúc bề mặt và hiệu suất phát xạ của chấm lượng tử carbon, Tạp chí Khoa học Đại học Sư phạm Hà Nội 2. 55 (2018) 67-74. 
[14] M.V.T. Hoàng Quang Bắc, Trần Thu Hương, Đinh Thị Châm, Nguyễn Thị Loan, Nguyễn Thị Quỳnh, Bùi Thị Huệ, Lê Thị Thùy Hương, Mai Xuân Dũng, Nghiên cứu tổng hợp hạt nano huỳnh quang từ một số rau củ quả, Tạp chí Hóa học và Úng dụng 4(40) (2017) 70-73.

[15] Y. Song, S. Zhu, S. Zhang, Y. Fu, L. Wang, X. Zhao, B. Yang, Investigation from chemical structure to photoluminescent mechanism: a type of carbon dots from the pyrolysis of citric acid and an amine, J. Mater. Chem. C. 3 (2015) 59765984. https://10.1039/C5TC00813A.

[16] T.H. Ngà, B.T. Hạnh, M.X. Dũng, Tính toán lượng tử làm rõ tính chất quang học của chấm lượng tử carbon, Tạp chí Khoa học - Đại học Sư phạm Hà Nội 2. 56 (2018) 24-31.

[17] S. Zhu, Q. Meng, L. Wang, J. Zhang, Y. Song, H. Jin, K. Zhang, H. Sun, H. Wang, B. Yang, Highly photoluminescent carbon dots for multicolor patterning, sensors, and bioimaging, Angew. Chemie - Int. Ed. 52 (2013) 3953-3957. https://doi:10.1002/anie.201300519.

[18] Q.B. Hoang, V.T. Mai, D.K. Nguyen, D.Q. Truong, X.D. Mai, Crosslinking induced photoluminescence quenching in polyvinyl alcohol-carbon quantum dot composite, Mater. Today Chem. 12 (2019) 166-172. https://doi: 10.1016/j.mtchem.2019.01.003. 